\title{
A Testimony to Muzil: Hervé Guibert, Foucault, and the Medical Gaze
}

\author{
Joanne Rendell ${ }^{1}$
}

Testimony to Muzil: Hervé Guibert, Michel Foucault, and the "Medical Gaze" examines the fictional/autobiographical AIDS writings of the French writer Hervé Guibert. Locating Guibert's writings alongside the work of his friend Michel Foucault, the article explores how they echo Foucault's evolving notions of the "medical gaze." The article also explores how Guilbert's narrators and Guibert himself (as writer) resist and challenge the medical gaze; a gaze which particularly in the era of AIDS has subjected, objectified, and even sometimes punished the body of the gay man. It is argued that these resistances to the gaze offer a literary extension to Foucault's later work on power and resistance strategies.

KEY WORDS: AIDS: HIV; medical gaze; Guibert; Foucault; power; doctor/patient relationship; gay; autobiography.

Muzil spent a morning in the hospital having tests done, and told me he'd forgotten how completely the body loses all identity once it's delivered into medical hands, becoming just a package of helpless flesh, trundled around here and there, hardly even a number on a slip of paper. (Guibert, 1994, p. 23)

This passage from Hervé Guibert's To the Friend Who Did Not Save My Life presents a preview of some of the principle concerns of this paper. First, on the extradiegetic level, the passage anticipates this paper's linking of Hervé Guibert with Michel Foucault. Guibert was a close friend of Foucault, and "Muzil" is Guibert's fictional name for the philosopher who, like Guibert, died of AIDS (Foucault died in 1984, Guibert in 1991). Although already an established writer and journalist in France in the late seventies and through the eighties, Guibert in fact only became widely known after the publication of To a Friend, a book which

\footnotetext{
${ }^{1}$ Address correspondence to Joanne Rendell, Institute for the Study of Genetics, Biorisks and Society, Law and Social Sciences Building, University Park, University of Nottingham, Nottingham NG7 2RD UK; e-mail: Joanne.rendell@ nottingham.ac.uk.
} 
recounts this friendship and aspects of Muzil/Foucault's life, illness and death, and which was received amid certain controversy. ${ }^{2}$ Second, the passage also depicts a subordinating and silencing medical gaze; a depiction which is important in the work of Foucault and pervades Guibert's AIDS works. It is also a depiction which Guibert's works, emulating the shift in Foucault's own work away from such repressive views of the gaze (and indeed of power more generally), ultimately move beyond. As this paper will demonstrate, Guibert's works negotiate the medical gaze in ways that not only echo Foucault's evolving notions of the gaze and interlinked notions of power, but also in ways that contest the gaze and in fact offer concrete examples of resistance strategies only really hinted at in the later works of Foucault.

It must be pointed out from the outset, however, that I do not seek to establish a "true" or directly causal link between Foucault's writings and the works of Guibert. Trying to establish the "real" Guibert, trying to determine his "real" influences, would be an onerous and ultimately futile task: as Jean-Pierre Boulé has comprehensively documented in his works on the author, Guibert continually and deliberately blurs the boundaries between truth and falsehood, reality and fiction. Rather, this paper will show how Guibert's AIDS works-To a Friend (TF), The Compassion Protocol (CP), The Man in the Red Hut (RH), Paradise (P), Cytomegalovirus (C) and the video diary/film "La Pudeur ou l'bnpudeur" (PI) can be seen to "converse" with Foucauldian notions of the medical gaze and, in a kind of "testimony to Muzil," offer up important challenges to it. ${ }^{3}$

This paper is not the first to suggest a relation between Guibert's writing and Foucault's conceptions of the medical gaze. ${ }^{4}$ Emily Apter (1993) hints at it in her essay "Fantom Images," when she relates descriptions of medical examinations in Guibert's texts, to Muzil/Foucault's description of "the loss of . . . identity" incurred by "medical probes and interventions" (p. 86). David Caron (1995), although not specifically citing Foucault, overtly makes the connection: "In his autobiographical novels, Guibert asserts patient's rights over their own discourse and exposes the

\footnotetext{
${ }^{2}$ Murray Pratt (1998) observes that initial "responses to the publication of To a Friend in France tended to view the inclusion of Muzil in tabloid terms, as a betrayal of the great man's secrets and as an outing of Foucault as gay, HIV positive and a practitioner of S/M" (p. 159).

${ }^{3}$ For citation purposes, in the rest of this paper I will use the abbreviations indicated. To a Friend was first published in France as À L 'ami qui ne m 'a pas sauvé la vie in 1990; The Compassion Protocol as Le Protocole compassionel in 1991; The Man in the Red Hat as L'Homme au chapeau rouge in 1992; Paradise as Le Paradis in 1992; and Cytomegalovirus as Cytomégalovirus in 1992. "La Pudeur ou 1'Impudeur" was first aired on French television on 30 January 1992. This paper will refer to these works as Guibert's "AIDS works" although it important to note that not all are wholly or directly concerned with the disease: for example, Paradise, which follows the travels of a young couple to Martinique, Bora Bora and Mali, only hints at AIDS through its continual recourse to issues of illness, disease and death.

${ }^{4}$ Critics have also more generally linked Guibert's work to that of Foucault. Ralph Sarkonak, for instance, after detailing the friendship between the two men, asserts: "much of Guibert's work can be read as a fictionalization of Foucault's theories. For example, Des aveugles is based on Guibert's experiences as a volunteer at an institution dating back to the nineteenth century whose prison-like atmosphere is underscored by the fact that the young people housed there are blind. As Edmund Smyth has argued, this roman noir is a "continuation" of Foucault's Surveiller et punir" (1996, p. 180).
} 
inherent violence of a relationship that makes them the passive object of the medical gaze.... For Guibert, who was also a photographer, the greatest violence is that of the medical gaze" (p. 239).

Perhaps in the most explicit linking of Guibert's works with Foucault, Murray Pratt (1998) explores how Guibert's hospitalization diary, Cytomegalovirus, details "its author's confrontation with the medical gaze" (pp. 159-161). Importantly, Pratt also goes on to investigate how the "resistance" that this text poses to, among other things, the medical gaze, is the kind of "resistan[ce] practice envisaged by Foucault" (p.159). Looking at a number of Guibert's AIDS works, and also looking in more specific detail at pertinent writings of Foucault, this paper will explicate further Pratt's thesis and explore the way Guibert's work not only negotiates the medical gaze but also offers up "Foucauldian" resistances to such a gaze.

Foucault's earliest explication of the "medical gaze" occurs in his study, The Birth of the Clinic (1972). In what he elsewhere defines as an archaeological investigation (an investigation which seeks to locate discourses, such as medical discourses, within the specific historical, institutional, social and economic relations through which they emerge),${ }^{5}$ this study examines the "birth" of the modem "clinical experience;" it is, he asserts, an "historical and critical investigation" concerned with "determining the conditions of possibility of medical experience in modem times" (1972 p. xix). Foucault's study focuses specifically on the period at the end of the eighteenth and beginning of the nineteenth century, where he observes a shift in the way disease and illness were formulated and thus how they were then treated. He demonstrates that before this period the "classificatory rule dominates medical theory and practice" and where the maxim, "Never treat a disease without first being sure of its species," was central (1972 p. 4). He then shows that from the nineteenth century onwards such an approach was replaced by a medical theory and practice based around the "seen" and the "spoken," the "perceptible," and the "statable" (1972, p. 95). Foucault argues that the introduction of pathological anatomy and the reorganization of the "clinic" into a place of observation and learning (as well as a place of healing) replaced classifactory medicine, and led to the ascendency and "sovereignty of the gaze" in modem medical experience (1972, p. 89). He is careful to clarify that this shift was not some sort of epiphany where doctors, "free at last of theories and chimeras, suddenly agreed "to approach the object of their experience with the purity of the unprejudiced gaze" (1972, p. 195). He argues instead, that the shift was "nothing more than a syntactical reorganization of disease in which the limits of the visible and the invisible follow a new pattern" (1972, p. 195).

The medical gaze in this new "syntactical reorganization," according to Foucault, is understood to be "pure of all intervention" and is seen to generate "only the

\footnotetext{
${ }^{5}$ In his text The Archaeology of Knowledge, Foucault (1989) defines his "archaeological" method as "seeking to discover the whole domain of institutions, economic processes, and social relations on which a discursive formation can be articulated" (p. 164).
} 
syntax of the language spoken by things themselves in an original silence" (1972, pp. 107-109). It is a gaze which, in this supposed "purity," can "bring truth" about the body "to light" (1972, p. xiii). Medical discourse is simply the description of what this "pure" gaze perceives in its observations of the body. Owing to this governance of the gaze, Foucault argues that the modem "clinical experience" increasingly becomes "a simple, unconceptualized confrontation of a gaze and a face, or a glance and a silent body; a sort of contact prior to all discourse, free of the burdens of language, by which two living individuals are 'trapped' in a common, but non-reciprocal situation" (1972, pp. xiv-xv). Under the scrutiny of the gaze, in other words, under the observation of the "eye that knows and decides," the "eye that governs" and the "eye" that dissects, "isolate[s]" and "classif[ies]", the patient becomes the passive and silent object of knowledge (1972, p. 89).

Although Foucault hints that in the "interests of an open-market" modem "liberal medicine" is reviving "old rights of a clinic understood as a special contract, a tacit pact" made between doctor and patient (1972, p. xiv), Guibert's depictions of encounters with the medical gaze demonstrate that a subordinating, silencing and non-reciprocal gaze is still far from extinct. In The Compassion Protocol, for example, the narrator describes the violence and humiliation of a fibroscopy: ${ }^{6}$

\begin{abstract}
At once a distracted student nurse, to whom Dr Domer... is issuing orders from a safe distance, stuffs this thick tube into my mouth and forces it past my uvula so as to shove it down inside me. I'm suffocating, I cannot take the tube they are thrusting down my trachea until it reaches my stomach, I have spasms, contractions, hiccups, I want to reject it, spit it out, vomit it out of me, I am slavering and groaning (CP, p. 46).
\end{abstract}

This episode depicts both the repressive power of the gaze and also its silencing power which not only renders the narrator mute during the procedure, but leaves him "speechless" after he leaves the hospital (CP, p. 48). This episode is an extreme example, but throughout all of Guibert's AIDS works there is a continual depiction of an intruding and disempowering medical gaze. The narrator of To a Friend, for example, when awaiting his test results, talks about his "blood" being "stripped naked and laid bare" (TF, p. 6). The narrator of Cytomegalovirus feels his body is continually exposed when he realizes that the "window" between his hospital room and the corridor "permits permanent viewing" (C, p. 5). In Paradise, the narrator describes the horror of having to "crawl" through "sterile" and "isolating chambers" in order to have his brain scanned and gazed at by, what he depicts as, a monstrous and "famished" machine (P, p. 51).

\footnotetext{
${ }^{6}$ This paper will refer only to the "narrator" of Guibert's texts as it is problematic to assume that the "I" of Guibert's texts it Hervé himself. Emily Apter (1993) observes that Guibert's novels "are neither fiction nor pure autobiography" (p. 83), and corroborating this point, Clara Orban (1999) observes, in respect to Guibert's Fou de Vincent (not yet translated into English), how this problematizes the narrative "I": "As is often the case in Guibert's work, the narrator bears heavy traces of an autobiographical "I," although there is almost always something suspect with this "I", making the reader believe that what seems to be autobiography is really fiction" (p. 132).
} 
It is also no coincidence that not long after describing a rather grisly operation in which doctors remove part of a ganglion from his neck in order to have it observed under the microscope, the narrator of The Man in the Red Hat more than once describes the intrusive antics of the flies in Greece: "the probes of flies clinging to my skin to pump out its secretions tickled it disagreeably, they were exploring my nostrils, copulating with a great buzzing in my ears, trying to force their way between my eyelids to suck the jelly of my corneas" (RH, p. 47). This passage not only alludes to those doctors who "injected," "slit," and took samples from the narrator's throat in his earlier operation (RI-I, pp. 23-24); it also provides images of flies "copulating" and sucking "jelly" from the narrator's eyes, powerfully alluding to sexual assault. The passage, like the fibroscopy episode in The Compassion Protocol with its allusions to oral rape, hints at a notion of the medical gaze as not only intrusive and silencing but also as sexually violating. In fact, these passages appear to hint at not only a sexually violating gaze but also a gaze which punishes and represses, paradoxically in a sexual way, the sexuality of Guibert's narrators who are all gay men with AIDS.

Foucault's notion of the medical gaze is explicated and developed further amid his more general discussions in Discipline and Punish (1975/1991). This text, which has an overall aim to investigate the "scientifico-legal complex from which the power to punish derives its bases, justifications and rules," moves from an "archaeological" investigation of changes in penal practices, to a more general exploration of, what Foucault calls "disciplinary power" (199 1, p. 23). Focusing again on the end of the eighteenth century, Foucault argues that this period saw a rise in the productivity of power and, in particular, a rise in a particular kind of power exercised on bodies in "disciplines" such as the army, hospitals, schools and prisons (1991, p. 137). Replacing a model of "sovereign" power, this "new" disciplinary power, he argues, works at multiple sites and meticulously controls, invests in and subjects bodies through the techniques of surveillance, normalization and examination. The medical gaze becomes, in Discipline and Punish, a crucial instrument of this disciplinary power and a central feature in the "disciplinary society" (1991, p. 209). Like other surveillance techniques in respective disciplines, the medical gaze observes, normalizes, examines and ultimately makes "docile" the bodies in its sights/sites (1991, p. 138).

Once again Guibert's depiction of the medical gaze echoes this more refined Foucauldian depiction. Early in To a Friend, for example, Guibert's narrator reflects on his doctor's repetitive way of examining him: "Dr. Chandi . . . performed the same procedures in the same order each time he examined me: after the usual taking of blood pressure, he would check the soles of my feet, the skin between my toes, delicately inspect the opening of the ever-so-sensitive urethra" (TF, pp. 10-11). The examination, according to Foucault is a key component of the gaze (and more widely of disciplinary power), as it "combines the techniques of an observing hierarchy and those of a normalizing judgment," and also "establishes over individuals a visibility through which one differentiates them and judges 
them" (Foucault, 1991, p. 184). This is why, he argues, the "examination is highly ritualized" (p. 184). This passage in To a Friend reenacts this ritualization, not only in the description of the procedure, but also in the repetitive, list-like and paratactic way it is described. Such a formalized procedure of "checking" and "inspecting" is echoed in The Compassion Protocol, where the doctor, Claudette Dumouchel, is described "scrutiniz[ing]" the narrator's "teeth," "tongue" and "palate" (CP, p. 38). The same doctor's ritualized and almost hypnotic examining technique is captured graphically in Guibert's film "La Pudeur ou L'Impudeur," where she is filmed (although always with her back to the camera or her face obscured) testing and scrutinizing the obedient Guibert.

As Caron (1995) observes, the initial reaction of Guibert's narrators towards this examining and silencing gaze is "one of refusal"; they refuse to be "photographed" and "weighed," and refuse to submit to "painful exams" (p. 240). The narrator of Cytomegalovirus even refuses to wear the revealing "blue paper gown" on his way to surgery, and tells the nurse that the only way she could get him to wear such an article would be "to accompany" him, "hand in hand, in the same outfit" (C, p. 48). This gesture of refusing the gaze, although a practice of resistance that Guibert's narrators ultimately move beyond, is an important one. In On Deconstruction, Jacques Derrida (1981) describes the "violent hierarchy" that constitutes binary oppositions, pointing out that to "neglect" a "phase of reversal" is "to forget that the structure of the opposition is one of conflict and subordination and thus to pass on too swiftly, without gaining any purchase against the former opposition, to a neutralization" (pp. 41-42).

The gestures of refusal by Guibert's narrators are important in that, like the reversing of binary oppositions that Derrida proposes, they expose the power structure behind the patient/medical gaze (object/subject) relation. As Lawrence Schehr (1995) observes, however, the "modem disease" of AIDS "needs modem medicine," and Guibert's narrators, in their attempts to evade illness, ultimately submit to the "invasion," "internment," and even "rape" of medicine (p. 175). Nevertheless, even though Guibert's AIDS bodies no longer refuse the medical gaze, they increasingly negotiate the gaze and ultimately offer up resistance strategies to it. Beyond outright refusal, and in a shift that echoes Foucault's own evolving notions of power, Guibert's narrators and, in fact, Guibert himself as writer/director, challenge the workings of the medical gaze.

Aside from positing this more elaborated notion of the medical gaze, Discipline and Punish also introduces Foucault's notion of power as multiple, productive and open to resistances, a notion he will develop more fully in The History of Sexuality (1976). Although the disciplinary power model in this work may initially appear pessimistic in its seemingly deterministic creation of "docile" bodies that are perpetually subjected by the gazes of the disciplines such as medicine, this text begins to sketch a notion of power that contains within it the possibilities of resistance. Most crucially, Discipline and Punish introduces Foucault's linking of 
power with knowledge:

We should abandon a whole tradition that allows us to imagine that knowledge can exist only where the power relations are suspended and that knowledge can develop outside its injunctions, it demands and its interests. ... We should admit rather that power produces knowledge (and not simply by encouraging it because it serves power ... ); that power and knowledge directly imply one another; that there is no power relation without the correlative constitution of a field of knowledge, nor any knowledge that does not presuppose and constitute at the same time power relations. (1991, p. 27)

Power, then, is not simply prohibitive or repressive force but is in fact (with knowledge) a productive set of "relations": power produces knowledge; knowledge produces power. As well as its relational and productive aspects, Foucault also suggests that power is not centered or exercised in one place or in one body (as it was in the times of "sovereign power"), but is in fact disparately, contingently and multiply exercised. Power is enacted through the repetitive and localized processes, within the varied and multiple disciplining institutions such as "schools," the "military," and the "hospital" (1991, p. 138). Although any discussion of resistance to such power is practically non-existent in Discipline and Punish, Foucault does hint at possibilities of resistance, when he observes that "this power is not exercised simply as an obligation or a prohibition on those who 'do not have it;' it invests them, is transmitted by them and through them; it exerts pressure upon them, just as they themselves, in their struggle against it, resist the grip it has on them" (1991, p. 27). Foucault hints here that, although subjects are invested within power, they are also capable of struggling "against it" and resisting its "grip."

The possibilities of such resistance are more prominent, however, in the depictions of power that follow in Foucault's later work, The History of Sexuality (1976/1990). In this study, Foucault much more explicitly outlines a notion of power as a "multiplicity of forces relations" that are "always local and unstable" (1990, pp. 92-93). He also asserts that this power, instead of being exercised only in the disciplines, is "exercised from inumerable points" (1990, p. 93). Importantly, he adds that "where there is power, there is resistance" (1990, p. 95). Resistance and power, in other words, are co-constitutive and thus there are a "plurality of resistances" that "everywhere in the power network" (1990, p. 95). Foucault is quick to clarify, however, that:

this does not mean that they [resistances] are only a reaction or rebound, forming with respect to basic domination an underside that is always passive, doomed to perpetual defeat. ... They are the odd term in the relations of power; they are inscribed in the latter as an irreducible opposite. Hence they too are distributed in irregular fashion: the points, knots, or focuses of resistance are spread over time and space at varying densities, at times mobilizing groups or individuals in a definitive way, inflaming certain points of the body, certain moments of life, certain types of behavior. (1990, p. 96)

Although more affirmative about the possibilities of resistance, Foucault is keen to stress that these "points" or "knots" of contestation manifest unequally and 
take widely differing forms. It is only the "strategic codification of these points of resistance," he argues, that "makes revolution possible" (1990, p. 97).

Despite these more elaborated and "optimistic assertions" about the power/ resistance dynamic, critics such as Jon Simons (1995) have argued that Foucault's arguments about the possibilities of resistance are "unconvincing in comparison with his portrayals of domination" (p. 83). According to Simons, Foucault not only "fails to elaborate much" on these capacities for resistance, but also his analyses of resistance are not engaged with "contemporary modes of government and subjection" (p. 83). In Foucault's later interviews and essays, Simons acknowledges that Foucault does begin to single out some practices as offering resistance: practices such as sadomasochism and certain modernist art and literature that, "without attempting to exist beyond" power, expose and work on the contingencies, limits and instabilities of power (pp. 68-70). Through his readings of Greek and Hellenic cultures in the later volumes of The History of Sexuality, Foucault also begins to formulate notions of resistant or contesting "forms of subjectivation" or "practices of self' (Foucault, 1987, p. 30). ${ }^{7}$ Foucault's death from AIDS, of course, cut short any further explications of resistance.

In enacting resistances to the modern medical gaze, Guibert offers up further elaborations to Foucauldian notions of resistance. Guibert's works demonstrate the patient is not wholly or necessarily made "docile" by the gazes of medicine, and that there can be opportunities to contest the subjections of medical surveillance. Most obviously, such resistances are enacted through the use of film. Despite initial reluctance from their doctors, the narrators of both The Compassion Protocol and The Man in the Red Hat choose to video their clinical experiences (CP, pp. 197-198; RH, p. 23). The video gaze in these episodes not only provides a competing gaze, thereby undermining the power structures within the examining or operating room, but also can be interpreted as a imitative gaze. Just as the appropriation of doctor's clothing by the narrator of Cytomegalovirus constitutes a subversive imitation and repetition of the "symbolic construction" of the "doctor" and "patient" roles (Caron, 1995, p. 239), so the introduction of the video gaze in these episodes disrupts or undermines the medical gaze by echoing its repetitious or imitative structure. By introducing another gaze, in other words, the narrators expose and also disrupt the way that the medical gaze, despite its ongoing technological advancement, has to continually reiterate and reproduce itself. Some of these videoed scenes constitute part of Guibert's film "La Pudeur ou L'Jmpudeur", and this sense of competing and imitating gazes becomes even more explicit in this context. In one episode, for example, Guibert is captured viewing the video of

\footnotetext{
${ }^{7}$ These later volumes of The History of Sexuality investigate the different "techniques of self' practiced in Antiquity. Although concerned not to revere or promote such 'techniques of self,' Foucault does hint that the precept of "taking care of self" (the predominant mode of subjectivation in Ancient cultures) is perhaps one that has resistant or subversive possibilities and which has been underemphasized in modem societies where the maxim "know yourself" has come to dominate (Martin, Gutman, \& Hutton, 1988, p. 19).
} 
his own throat operation, a scene described in The Man in the Red Hat. The gaze of the surgeons working on the anaesthetized Guibert is echoed and repeated by not only the presence of the video camera in the operating theatre but also by the later gaze of Guibert himself and the gaze of the "La Pudeur's" viewers.

In a similarly imitative fashion, resistance is also enacted through parody or imitation of the sexualized and sexualizing nature of the medical gaze. Guibert's works, as we saw earlier, hint at the sexual intrusiveness of medical surveillance and suggest a gaze that paradoxically punishes (homo)sexuality with this sexual intrusiveness. This is reminiscent of Foucault in the first volume of The History of Sexuality where, as Judith Butler (1997) summarizes, he argues that the repressive operation of the law is undermined "precisely through becoming itself the object of erotic investment and excitation" (p. 101). Disciplinary apparatus such as medicine, Foucault argues, precisely because it is sexualized, becomes the "occasion for incitement of sexuality" and, therefore, undoes "its own repressive aims" (p. 101). ${ }^{8}$ The narrator of The Compassion Protocol, in his interactions with his doctor, Claudette Dumouchel, imitates and exposes the erotic and eroticizing nature of the medical gaze first by highlighting the eroticized nature of his own (imitative) video gaze. In what reads like screen directions for his own erotic movie, the narrator observes, "I undress and get into the picture. Claudette joins me" (see Caron, 1995,247). ${ }^{9}$ Second, the narrator plays on the erotic nature of the examination, that is, the erotic nature of medicine's chief instrument of surveillance. During one examination where Dumouchel lifts the "elastic" on his "briefs" to "palpate" his stomach and then goes on to manipulate his feet and tap and brush his body with her "finger-tip," the narrator describes how, with eyes closed, he "breathe[s] vigorously" and "pants" out responses to these procedures (CP, pp. 36-37). Just as the narrator of Paradise dares to point out to the "inventor" of the "deafening" and puslating brain scanner that this machine that seeks "in the brain traces of breakdown, possibly madness," in fact, itself "drives people mad" (P, p. 53), so the narrator's overtly sexualized responses to Dumouchel's examination in The Compassion Protocol dares to point out and parody the eroticized nature of the doctor's supposedly objective surveillance.

Despite the power of these resistances to expose the workings and contradictions of the gaze, it could be argued that to write or to film the experiences of illness and the body, as Guibert does extensively, is to ultimately corroborate and thus reinforce the power of the medical gaze. As David Armstrong (1983) points out in his text Political Anatomy of the Body, which considers and updates the Foucauldian

\footnotetext{
${ }^{8}$ Judith Butler (1997) discusses this argument in The Psychic Life of Power, and suggests that it is perhaps Foucault's uncovering of this "relationship of sexuality to power" that allows him to argue more explicitly in The History of Sexuality (than in Discipline and Punish) for "the possibility of resistance" (p. 101).

${ }^{9}$ When discussing how Guibert's text reveals the "interdependence" and role-like nature of the doctorpatient relationship, Caron (1995) points out that this is a "closer translation" of Guibert's words than James Kikup's translation that reads, "I undress, I put myself in the shot. Claudette comes and stands beside me" (CP, p. 198).
} 
notion of the medical gaze, the drive in modem medicine to encourage patients to "speak" their illness and to "speak" their body, although seemingly empowering and a move away from non-reciprocal clinical experiences, is actually another tool of the extended gaze (pp. 107-111). The testimony of the patient, Armstrong argues, becomes just another "whisper" in the "great confession" through which persons and their bodies are offered up to the gaze and are thus scrutinized, determined and subjected (p. 117). This was particularly apparent, as Cindy Patton (1990) observes, in the medical/epidemiological response to AIDS, where gay men, encouraged to "confess" the stories of their bodies, soon became labeled and thus stigmatized as one of society's "risk groups" (p. 55). Guibert's AIDS works, however, do more than just "confess" or, as Boulé (1999) argues, lay "bare" the body and illness "on the page" or on screen (p. 2). At the same time as they deliberately confuse notions of autobiography and thus confessional narratives, and at the same time as they depict resistances to the gaze, Guibert's writings and film also in themselves offer up resistances to the gaze in the way that they expose the workings and structures of medical surveillance.

First, Guibert's works contest the anatomizing and dissecting medical gaze in the way they mimic and ultimately reclaim such procedures into the realms of writing and film. Documenting the body is an ongoing concern in Guibert's works, including his pre-AIDS writings. Boulé (1999) argues that such documentation ultimately allows Guibert to "embrace" his sick body (p. 215). Beyond this rather individualistic interpretation, it can also be argued that Guibert's "baring" of the body imitates, exposes and also usurps the dissolutions and fragmentations of the ever more dissecting techniques of medical surveillance. Just as Claudette Dumouchel scrutinizes the narrator's body in The Compassion Protocol, so the narrator himself scrutinizes his own body. As Boulé observes, "on the very first page of the book [CP], the narrator describes how his body is wasting away and enumerates the things he can no longer do. . . The body becomes the corpus: one section begins with the narrator's weight, another with his temperature" (p. 214). The narrator, who admits a fascination with the "dissection table" and who admits to "dissecting" his "soul" through writing, also dissects and anatomizes his body in writing in the same way that the medical gaze dissects the sick body (CP, p. 67).

Aside from mimicking the anatomizing nature of medical surveillance, Guibert's works also challenge it by allowing death to figure prominently in the processes of his own writerly and filmic dissections. Foucault argues in The Birth of the Clinic (1973) that the ascendency of the gaze in medical practice coincided with the introduction (by Bichat) of the procedures of autopsy and pathological anatomy (p. 122). He argues that this necessarily "integrated" death into the "technical and conceptual totality" of medicine: "death" meant disease could be "both spatialized and individualized," which contributed to the self-present and ontological figuring of "Man" (pp. 146-159). Although death is the crucial component in the medicalization of the body, modem medicine has and continues to disavow its 
presence. Catherine Waldby (2000) argues this in her recent study on the Visible Human Project, where she demonstrates how this very recent biomedical resource covers over its (ultimately quite gruesome) use of corpses by dressing the project up in the rhetoric of life, Genesis and the figurations of Adam and Eve (chapters 5 and 6). ${ }^{10}$ Guibert's works, on the contrary, document the body in a way which continually acknowledges the encroachment of death. His narrators openly admit the specter of death in their examinations of their bodies. In To a Friend, for instance, upon examining himself in front of a mirror, the narrator reports that he would have to "get used to this cadaverous face" and this face that "belongs no longer to me but to my corpse" (TF, p. 223). Similarly, the narrator of The Compassion Protocol observes a figure "en route to the tomb" in the reflection cast back by his mirror (CP, p. 7). This same narrator also admits the presence of death in the very possibility of his ongoing "dissections" and writings of his "body" and soul." He admits he can "work at this job" only with the aid of the "dead dancer's DDI" secured unofficially for him by a friend (CP, p. 67). Where medical practice disavows death, Guibert's narrator avows that death allows dissection.

In their processes of bodily dissection and documentation, Guibert's AIDS works also continually cite medical terms. His works consequently appropriate another crucial component of the gaze: its language or discourse. As Foucault points out in The Birth of the Clinic (1972), the medical gaze does not simply "look," it also names; it is an "alliance" between "words and seeing" (p. xii). Following the narrator of The Compassion Protocol, who pointedly learns "medical jargon perfectly" in order not to feel like "a little boy in front of whom the grownups speak a foreign language" (CP, p. 89), Guibert as writer/director cites this "medical jargon" in the realms of film and the literary, and therefore, as Schehr (1995) points out, "intemalize[s]" and "diffuse[s] it" (p. 176). Also, his constant repetition of acronyms such as DDI and AZT in paragraphs and sentences of, for example, The Compassion Protocol (CP, p. 69), importantly expose the iterable structure, and thus the contingency and instability, of such medical terms.

Perhaps most powerfully, Guibert's works challenge the power structures and hierarchies of the medical gaze by capturing the medical in its own gaze. Not only are Claudette Dumouchel and the surgeons of the throat operation caught in the gaze of Guibert's video camera (and thus, even if obscured, made characters of his film "La Pudeur ou L'bnpudeur"), so these and other medical figures are caught in Guibert's "writerly gaze." The impact of this capture is powerfully highlighted in Cytomegalovirus, when after a doctor admits she knows Claudette Dumouchel,

\footnotetext{
${ }^{10}$ The Visible Human Project, authored by the National Library of Medicine in the United States and commenced in 1991, multiply dissected, photographed and converted into visual data files two human cadavers (one male and female) to create computerized, three dimensional recordings of these bodies. Waldby (2000) reports how the VHP data is now used widely in "schools," "universities," and by "medical staff and students" (p. 18). For images on the intemet see: http://www.nlm.nih.gov/research/visble.html
} 
the narrator replies with a certain glee, "I promise I wont write Le Protocole Compassionel \#2, so you can relax, we can have a nice relationship" (C, p. 5). Guibert's "writerly" and video gazes, offer something more than just a countering patient gaze. A whole army of resources, persons and efforts are deployed in the exercising of the modem medical gaze, making the power balance in the modem clinical encounter unequally weighted. In publicizing his gaze through video and published prose, Guibert begins to contest this inequality and pose a more collective counter gaze.

In a testimony to his friend Foucault's work, then, Guibert offers up an elaboration of some of those resistances that, as Foucault argued, exist everywhere within power. These particular resistances offered up by Guibert's works demonstrate that the patient, in particular the gay man with AIDS who has been so often blamed and stigmatized in discourses surrounding the disease, does not necessarily have to be "docile" or silenced in his confrontations with the medical gaze. Even more importantly, they also offer resistances which have collective ramifications. They not only contest the unequal balance of power in the clinical encounter by creating this collective counter gaze, they also posit a new kind of a exemplary patient subjectivity that refuses to be subordinated and exposes and works against the discourse and practices of the medical. Although such resistances may only be temporal and localized and may ultimately be reclaimed and reconstituted by power, they importantly reveal the power structures, contingencies and contradictions of this gaze that is often taken, particularly in its ongoing technological advancement, to be unquestionable. Guibert's resistances matter in the way that they, loyal to Foucault's own critiques of the mechanisms of power, expose and contest the workings of a modem AIDS "clinic."

\section{REFERENCES}

Apter, E. (1993). Fantom images: Hervé Guibert and the writing of "sida" in France. In T. Murphy, \& S. Poirier (Eds.), Writing AIDS: Gay literature, language and analysis (pp. 83-97). New York: Columbia University Press.

Armstrong, D. (1983). Political anatomy of the body: Medical knowledge in Britain in the Twentieth Century. Cambridge: Cambridge University Press.

Boulé, J. (1995). Hervé Guibert: A 1 ami qui ne m 'a pas sauvé la vie and Other Writings, Glasgow: University of Glasgow French and German Publications.

Boulé, J. (1999). Hervé Guibert: Voices of the self(J. Fletcher, Trans.). Liverpool: Liverpool University Press.

Butler, J. (1995). Bodies that matter: On the discursive limits of sex. London: Routledge.

Butler, J. (1997). The psychic life of power: Theories in subjection. Stanford, CA: Stanford University Press.

Caron, D. (1995). Playing doctors: Refiguring the doctor-patient relationship in Hervé Guibert's AIDS novels. Literature and Medicine, 14(2), 237-249.

Derrida, J. (1981). Positions. (A. Bass, Trans.). London: Athlone.

Foucault, M. (1972/1989). The archaeology of knowledge, (A. M. Sheridan Smith, Trans.). London: Routledge. 
Foucault, M. (1972). The birth of the clinic: An archaeology of medical perception (A. M. Sheridan Smith, Trans.). London: Tavistock Publications.

Foucault, M. (1975/1991). Discipline andpunish: The birth of the prison (A. M. Sheridan Smith, trans.). Harmondsworth: Penguin.

Foucault, M. (1976/1990). The history of sexuality: Volume one, an introduction (R. Hurley, Trans.). Harmondsworth: Penguin.

Foucault, M. (1984/1987). The use ofpleasure: The history of sexuality (Vol. Two) (R. Hurley, Trans.). Harmondsworth: Penguin.

Guibert, H. (1993a). The compassion protocol (J. Kirkup, Trans.). London: Quartet Books.

Guibert, H. (1993b). The man in the red hat (J. Kirkup, Trans.). London: Quartet Books.

Guibert, H. (1994). To the friend who did not save my life (L. Cove\&ale, Trans.). London: Serpents Tail.

Guibert, H. (1996a). Cytomegalovirus: A hospitalization diary(C. Oban, Trans.). New York: University Press of America.

Guibert, H. (1996b). Paradise (J. Kirkup, Trans.). London: Quartet Books.

Martin, L., Gutman, H., \& Hutton, P. (Eds.). (1988). Technologies of self: A seminar with Michel Foucuult. London: Tavistock Publications.

Orban, C. (1999). Writing, time, and AIDS in the works of Hervé Guibert. Literature and Medicine, $18(1), 132-150$.

Patton, C. (1990). Inventing AIDS. London: Routledge.

Pratt, M. (1998). A walk along the side of the motorway: Or, AIDS and the spectacular body of Hervé Guibert. In O. Heathcote, A. Hughes, \& J. S. Williams (Eds.), Gay signatures: Guy and lesbian theory, fiction and film in France 1945-1995 (pp. 51-172). Oxford: Berg.

Sarkonak, R, (1996). Traces and Shadows: Fragments of Hervé Guibert. Yale French Studies, 90, 172-202.

Schehr, L. R. (1995). Alcibiudes at the door: Guy discourses in French Ziteruture. Stanford, CA: Stanford University Press.

Simons, J. (1995). Foucuult and the political. London: Routledge

Waldby, D. (2000). The visible human project: Informutic bodies undposthumun medicine. London: Routledge. 